\title{
Metodologia Pedagógica e Tecnológica de apoio às demandas dos alunos nas atividades extraclasse
}

\author{
Cristiane Sanches da Silva ${ }^{1}$, Marcos da Fonseca Elia ${ }^{2}$, Danielle Santana Correia ${ }^{3}$ \\ ${ }^{1}$ C.E.S.A.R - Centro de Estudos e Sistemas Avançados do Recife, ${ }^{2}$ Programa de Pós \\ Graduação em Informática (PPGI) - Universidade Federal do Rio de Janeiro (UFRJ), \\ ${ }^{3}$ Desenvolvedora Autônoma \\ cristiane.sanches@cesar.org.br, melia@nce.ufrj.br, \\ danielle.santana@gmail.com
}

\begin{abstract}
This work tries to attend the demand of educators for solutions to support students in extracurricular activities, offering a pedagogical and technological approach, built in according to the guiding principle of coresponsibility. Its architecture includes the dynamics of the extracurricular teaching-learning process, the roles of each of the protagonist agents of this process, as well as a system for semi-automatic recommendation. A Web Learning Community Platform (PAE) was developed based on this architecture. Two case studies have been carried out suggesting a positive evaluation for extracurricular support given by platform (PAE) both in pedagogical and ergonomic aspects.
\end{abstract}

Resumo. O presente trabalho procura atender a demanda de educadores por soluções que apoiem os alunos no esclarecimento das dúvidas escolares em atividades extraclasse, oferecendo uma metodologia pedagógica e tecnológica, construída segundo princípio norteador da corresponsabilidade. Sua arquitetura inclui a dinâmica do processo de ensino-aprendizagem extraclasse, os papéis de cada um dos agentes protagonistas desse processo e um sistema de recomendação semiautomático. Foram realizados dois estudos de caso que apontam para uma avaliação positiva da Plataforma de Apoio Extraclasse (PAE) nos aspectos pedagógicos e ergonômicos.

\section{Introdução}

Nos diversos contextos educacionais ${ }^{1}$ (escolas públicas, particulares e espaços informais de educação ${ }^{2}$ ) é possível perceber que existe uma busca dos alunos, pais e escolas por espaços para apoio aos alunos nas atividades extraclasse e nas dúvidas escolares. Nossa experiência nos leva a afirmar que, ainda hoje, a maioria dos professores sente dificuldade em elaborar atividades que utilizem os recursos tecnológicos existentes no ciberespaço [Lévy 1999] de forma a colaborar com o aprendizado do aluno e este, por sua vez, tem dificuldade em encontrar um recurso que possa lhe dar suporte numa determinada demanda escolar.

\footnotetext{
${ }^{1}$ Roteiro de Observação da Escola realizado na disciplina MAB750 - Introdução à Informática na Educação, na turma 2012 do professor Fábio Ferrentini.

${ }^{2}$ Projeto Praça do Conhecimento - http://www.pracadoconhecimento.org.br
} 
As tecnologias digitais da informação e comunicação (TDIC) fazem parte do cotidiano contemporâneo e são ferramentas importantes no processo de cognição e aprendizagem na atual sociedade da informação. O ciberespaço oferece diversas possibilidades para a tecnologia educacional: vídeo-aulas, conteúdo interativo, livros didáticos, softwares educativos, redes sociais, são os chamados objetos de aprendizagem (OA). Apesar da grande quantidade de OAs disponíveis, sua utilização no processo educativo ainda é bastante restrita. Falta capacitação e informação aos profissionais desta área de como adequar esses objetos a sua pedagogia e aos alunos orientação de como buscar e utiliza-los em suas demandas.

Este trabalho apresenta uma metodologia pedagógica e tecnológica de apoio às demandas dos alunos nas atividades extraclasse, permitindo que eles possam fazer uso das TIC como suporte escolar através de dicas estruturadas na forma de prescrições, criando a possibilidade de um estudo dirigido sob a responsabilidade de mediadores. Para a consecução deste objetivo foi criada uma arquitetura que será discutida na seção 2 e que está sendo instanciada por uma "Plataforma de Apoio Extraclasse" (PAE) disponível na Web, a ser apresentada na seção 3.

Selecionamos alguns trabalhos apresentados em anos anteriores no Simpósio Brasileiro de Informática na Educação - SBIE que possuem semelhança com a proposta apresentada. Dentre eles estão "Um sistema inteligente baseado em ontologia para apoio ao esclarecimento de dúvidas" [Amorim et al 2011], que apresenta uma arquitetura de um sistema apoiada por ontologias que recebe perguntas e fornece respostas de forma automática. Nossa proposta vai além de dar uma resposta direta, ela indicará um OA para que o aluno possa sanar sua dúvida construindo por si seu conhecimento. Os outros dois trabalhos encontrados foram: "Desenvolvendo um Sistema de Recomendação de Objetos de Aprendizagem baseado em Competências para a Educação: relato de experiências" [Cazella et al 2012] e "Um Modelo para Recomendação de Objetos de Aprendizagem Baseado em Similaridade de Sessões" [Wiedemann et al 2013]. Novamente em ambos os trabalhos, a dúvida do aluno não está em questão, neles a recomendação é baseada nas competências ou na similaridade das sessões. A contribuição que a nossa proposta pode acrescentar em ambos os trabalhos é o refinamento da recomendação de OAs, que estando relacionada com uma dúvida tende a ser mais eficiente.

\section{Arquitetura Pedagógica}

O diagrama da figura 1 ilustra esquematicamente esta arquitetura, na qual o princípio norteador da corresponsabilidade é representado, metaforicamente, por uma nuvem que permeia toda arquitetura e a faz funcionar com o uso de recursos TDIC. Ela contém também a dinâmica de suas funcionalidades e o sistema de recomendação proposto.

O conceito de corresponsabilidade que permeia toda esta proposta, está relacionado com o estabelecimento de parcerias, é a instanciação desta interação sujeitosujeito e sujeito-objeto, propondo uma solução que seja flexível e que tenha a colaboração de todos os envolvidos neste processo: alunos, pais, professores, escola, universidade e governo. A corresponsabilidade não é somente um acordar entre as partes, estabelecendo-se regras básicas bem definidas, mas é uma atitude coletiva com regras e ações que devem ser modificadas e adaptadas ao longo do processo, proporcionando melhores condições de atuação a seus integrantes. 


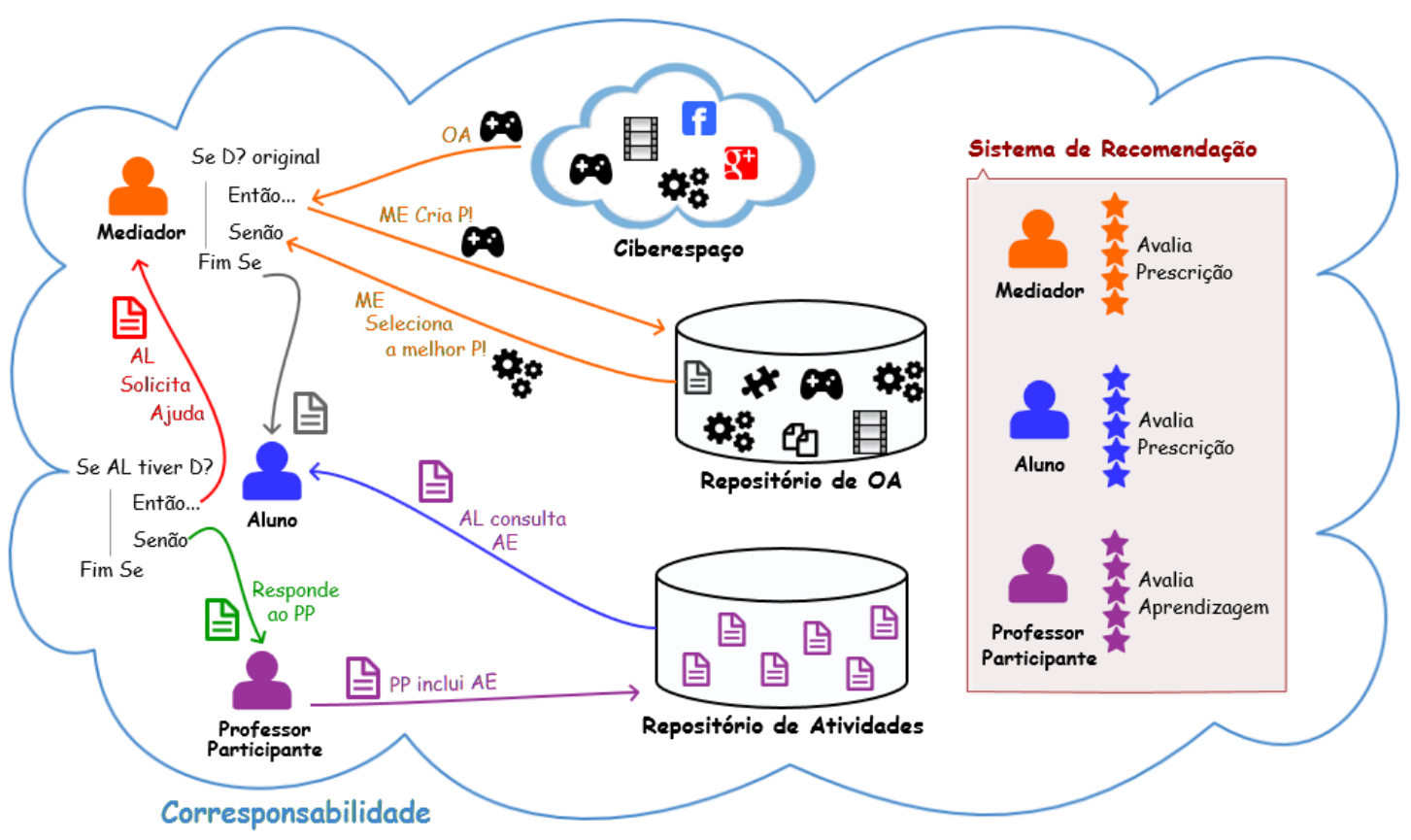

Figura 1. Arquitetura Pedagógica

Em relação à dinâmica das funcionalidades, na parte central da figura 1 vemos três repositórios, sendo que dois deles são residentes no próprio servidor do projeto e funcionam, respectivamente, como banco de atividades extraclasse (AE) e banco de dúvidas-dicas ( $\left.\mathrm{D}^{\text {? }}-\mathrm{D}^{!}\right)$, doravante denominadas prescrições $\left(\mathrm{P}^{!}\right)$. O terceiro encontra-se no ciberespaço de onde são obtidos OAs que serão usados nas atividades $\mathrm{AE}$ e/ou nas prescrições $\mathrm{P}$ ! Na parte esquerda da figura 1 vemos representados os agentes protagonistas desse processo (caricaturas): aluno (AL), professor-participante (PP) e mediador (ME). E na parte direita da figura 1 é mostrado sistema de recomendação de "atividades extraclasse-dúvidas-dicas", para que o aluno possa receber o apoio as suas dúvidas de forma mais adequada. Observe que a recomendação é baseada nas avaliações feitas pelos três protagonistas.

Interpretando o funcionamento da dinâmica proposta no que se refere ao processo de ensino aprendizagem, este se inicia com o professor-participante (canto inferior esquerdo) "registrando uma AE" no repositório de atividades. Em seguida o PP envia esta AE para seus alunos consultarem, via plataforma PAE. Espera-se então que os alunos da turma desse professor consultem as atividades AE disponíveis e tentem resolvê-las. Os alunos que souberem resolver a atividade deverão respondê-la ao PP,

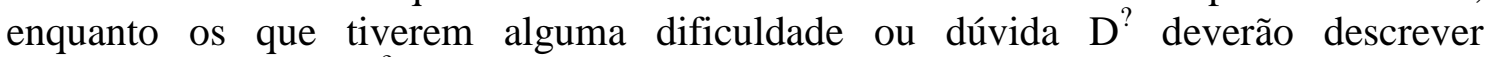
resumidamente esta $\mathrm{D}^{\text {? }}$ e enviá-la para o ME. Com base nesta descrição feita pelos AL, o ME terá a sua disposição um software de busca existente na plataforma PAE que irá verificar as $\mathrm{P}^{!}$mais similares com a $\mathrm{D}^{\text {? }}$, através de uma análise lexical:

1. Retiram-se as "stop words" da descrição textual da dúvida D? feita pelo AL.

2. Indexam as palavras remanescentes.

3. Compara-se a lista indexada gerada para a dúvida $D^{?}$ em tela com às palavraschaves das prescrições $\mathrm{P}^{!}$já existentes no repositório.

4. Selecionam-se as prescrições $\mathrm{P}^{!}$que apresentam superposição de palavras. 
Neste momento caberá ao mediador decidir se aproveita alguma das recomendações sugeridas pelo sistema ou se prescreve uma nova $\mathrm{P}^{!}$no sentido de atender as expectativas do aluno em resolver sua $\mathrm{D}^{\text {? }}$ e a envia para o aluno. Este processo pode ser recorrente, cabendo ao mediador encerrá-lo quando julgar conveniente. Após a conclusão de uma atividade, é necessário que sejam realizadas avaliações para alimentação do sistema de recomendação, conforme representado na parte direita escurecida do diagrama da figura 1.

Sob o ponto de vista do processo de ensino-aprendizagem-avaliação, as relações são diferenciadas: o professor-participante vai avaliar com um olhar direcionado para o resultado, ou seja, para a aprendizagem, o mediador e o aluno, por sua vez, vão avaliar uma prescrição em relação à dúvida, pois ambos esperam vê-la esclarecida. Com base nestas considerações, são construídos dois índices de recomendação, um referente à avaliação de processos que é feita pelo $\mathrm{ME}$ e pelo $\mathrm{AL}$, e outro referente à avaliação de produto, representada pelo resultado da aprendizagem que é avaliada pelo PP. A avaliação de processos tem mais a ver com percepções de expectativas, enquanto a avaliação do resultado tem a ver com percepções de aprendizagem.

\section{Plataforma web PAE}

$\mathrm{O}$ aluno (Figura 2) ao visualizar os detalhes de uma determinada atividade, tem as opções de: responder a atividade se souber (botão "Responder") ou solicitar ajuda ao mediador caso tenha dúvida (botão "Solicitar Ajuda"). Neste último caso uma caixa de texto se abre na tela (Figura 4) para que o aluno descreva e envie sua dúvida. Na Área do Mediador temos a tela de apoio ao aluno onde é possível visualizar com detalhe a sua dúvida (Figura 3). Para responder a esta dúvida o ME pode indicar uma prescrição já existente no sistema (Figura 5) ou se desejar pode elaborar uma nova prescrição.
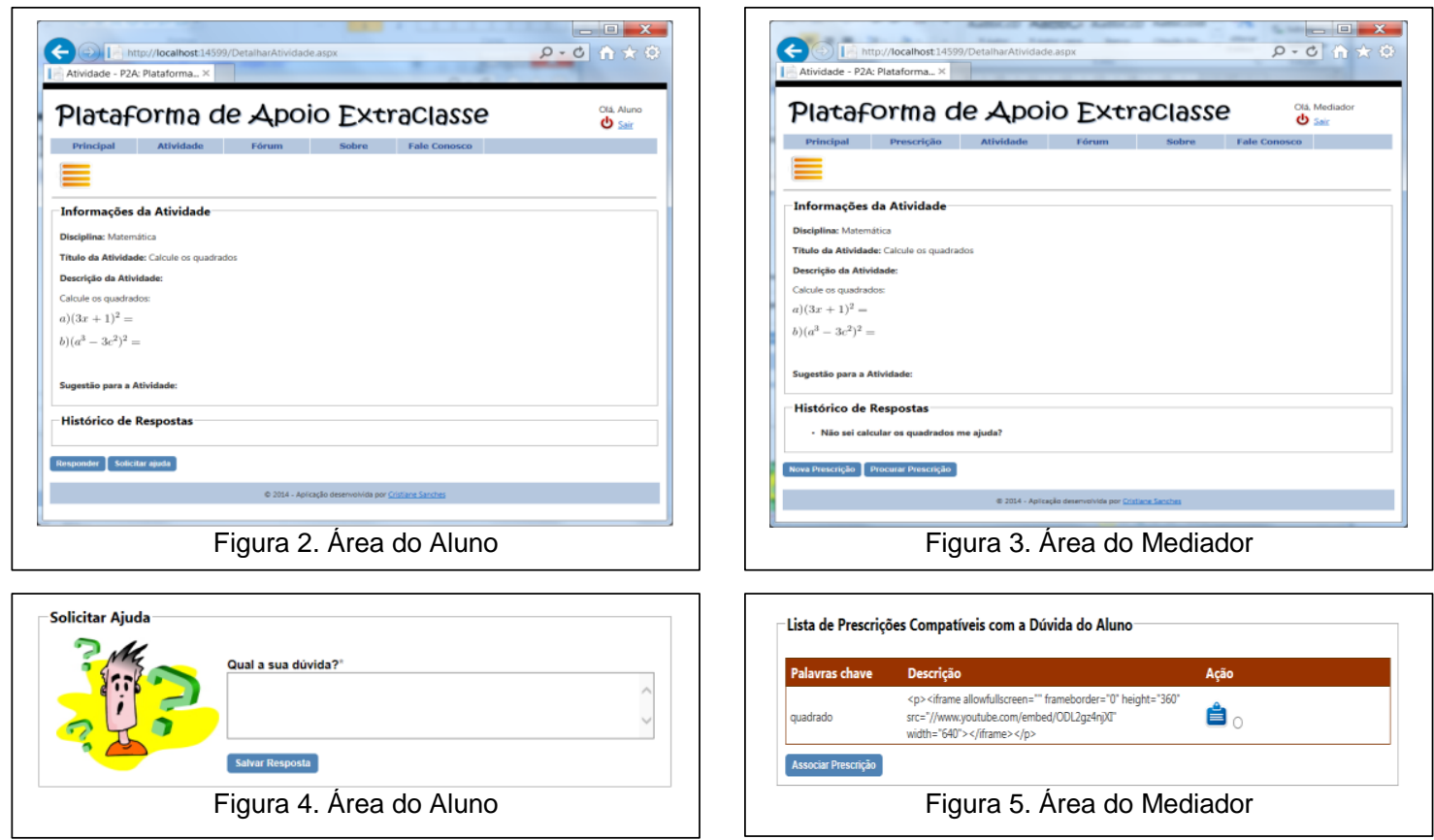

Para uma melhor compreensão da interface e de suas funcionalidades, navegue como visitante pela plataforma PAE (http://pae.nce.ufrj.br) usando como login/senha (professor/1234), (mediador/1234) ou (aluno/1234) para entrar respectivamente, como 
professor-participante, mediador ou aluno. Antes de iniciar o seu "tour" leia o manual que pode ser acessado na tela inicial.

\section{Estudos de caso de validação}

Foram realizados dois estudos de caso de validação da Plataforma Web PAE em dois cenários distintos, doravante identificados como Estudos de Caso A e B. O instrumento de validação escolhido para ser utilizado em ambos os casos foi o método proposto por Thomas Reeves (2003) que define 14 critérios pedagógicos e 10 critérios ergonômicos de avaliação. Em ambos os casos os avaliadores utilizaram a plataforma com um perfil distinto em cada momento da dinâmica (Professor-Participante, Aluno e Mediador).

O estudo de caso A foi realizado em uma Instituição de Ensino Formal (IEF) com vinte e quatro professores. Os resultados obtidos neste estudo de caso contribuíram para reforçar a importância do princípio da corresponsabilidade e apontaram algumas falhas pontuais no desenvolvimento da plataforma no que diz respeito à estrutura e a interface. No estudo de caso B foi utilizada uma amostragem por conveniência formada por alunos de um curso de Pós-Graduação em Tecnologias da Informação Aplicadas à Educação. Estes perceberam a presença de ambas as dimensões (ergonômica e pedagógica) na plataforma $\mathrm{PAE}$, sendo que a percepção da dimensão ergonômica foi mais forte. Nesta validação ficou claro que apenas uma interação entre aluno e mediador não é suficiente para atender a demanda do aluno, em $80 \%$ dos casos durante a validação ficou constatado que a dúvida do aluno é em relação à interpretação da atividade proposta. Assim a ferramenta permite "n" interações entre aluno e mediador para que uma dúvida seja resolvida. Foram realizados testes bem sucedidos em outros tipos de dispositivos móveis sugerindo que a plataforma PAE está pronta para ser utilizada em diferentes arquiteturas. A partir das respostas obtidas em ambos os estudos de caso, algumas funcionalidades da Plataforma foram corrigidas e ajustadas para atender de forma mais adequada aos seus usuários, tornando a navegação mais amigável.

Em relação a trabalhos e desdobramentos futuros vislumbramos a possibilidade de melhorar o software de busca das prescrições e que, na medida em que se tenha um repositório que armazene prescrições bem sucedidas, o sistema de recomendação possa ser refinado e faça o cruzamento desta informação com o perfil do aluno ou ainda com o seu perfil de navegação, abrindo assim uma janela para pesquisas de desenvolvimento de modelos teóricos para o "Aluno com dúvidas" e o "Mediador", aprimorando assim o sistema de recomendação das prescrições.

\section{Referências}

Lévy, P. (1999). Cibercultura. São Paulo: Editora 34.

Amorim, M. T. C. F. et al. (2011). Um sistema inteligente baseado em ontologia para apoio ao esclarecimento de dúvidas. Anais do XXII SBIE.

Cazella, S. C. et al. (2012). Desenvolvendo um Sistema de Recomendação de Objetos de Aprendizagem baseado em Competências para a Educação: relato de experiências. Anais do XXIII SBIE.

Wiedemann, T. et al. (2013). Um Modelo para Recomendação de Objetos de Aprendizagem Baseado em Similaridade de Sessões. Anais do XXIV SBIE. 